Geopolítica(s) Revista de estudios sobre espacio y poder ISSN: 2172-3958

\title{
¿Cambio o continuidad velada?
}

Yamandú Acosta, Alejandro Casas, Oscar Mañán, Alicia Rodríguez y Virginia Rossi (coords.) (2014) Sujetos Colectivos, Estado y Capitalismo en Uruguay y América Latina. Perspectivas Críticas. Montevideo: Ediciones Trilce, 312 pp. ISBN: 978-9974-32-640-8.

Esta obra, producida por el Núcleo-red Pensamiento Crítico en América Latina y Sujetos Colectivos (Núcleo-red), que nace en el seno de la Universidad de la República de Uruguay en 2009, aborda y da cuenta de las transformaciones y la coyuntura sociopolítica de América Latina, con particular atención al caso uruguayo. El Núcleo-red emprende una labor de aproximación a las distintas problemáticas a partir una perspectiva regional e interdisciplinar desde el pensamiento crítico. Sujetos Colectivos, Estado y Capitalismo en Uruguay y América Latina, aparece, como bien lo exponen Alfredo Falero y Luis Giménez en la presentación, por la necesidad de abordar los procesos de construcción de sujetos colectivos y la relación de éstos con el Estado y la democracia, así como por tomar y renovar los aportes del pensamiento crítico latinoamericano, y ello en diálogo con los diferentes modelos de desarrollo que se encuentran en conflicto en la actualidad.

El libro se encuentra divido en cinco ejes temáticos con capítulos colectivos en su mayoría. El primer eje inicia al lector en el tema desde una perspectiva regional, para centrarse los cuatro ejes restantes en el abordaje de las problemáticas del Uruguay contemporáneo.

Así pues, el primer eje abarca una con una vasta discusión conceptual y de forma sobre el capitalismo, el papel del Estado y los procesos de democratización en la región. Los diferentes capítulos del eje analizan la relación de la democracia y el capitalismo en el contexto regional, con especial consideración a los países con gobiernos caracterizados de progresistas.

Las movilizaciones, así como las grietas abiertas entre movimientos sociales y los nuevos gobiernos progresistas o de izquierda social, como sucediera con los casos ecuatoriano y bolivariano, evidencian el fin de un ciclo de confluencia entre movimientos sociales y gobiernos. En esta línea, Alfredo Falero, en el primer capítulo del primer eje, sostiene que la región se encuentra en un período bisagra: "podemos estar visualizando el inicio del fin de ese proceso sociohistórico” (p. 23). Falero realiza una tipología de la contención de los procesos de cambio por parte de los gobiernos caracterizados de progresistas, los cuales se valen de prácticas y estrategias que llevan a la indiferencia, la conformidad y la delegación, para la reproducción de la estabilidad sistémica. 
Por su parte, Yacmandú Acosta realiza una crítica a la democracia liberal desde la perspectiva de la función utópica, la cual visualiza a las constituciones "como objetivaciones discursivas en el proceso de construcción de sujetos, así como del Estado y la democracia en cuanto mediaciones institucionales a través de las que dichos sujetos se constituyen” (p. 35). En este sentido, según el autor, se estaría produciendo un giro transmoderno que implica a sujetos, Estado y constituciones, así como democracias que se constituyen por la interacción entre los tres elementos. Este giro transmoderno es fundamental "como posibilidad de la otredad de las que se propone caracterizar como «otras democracias»"1 (p. 36). Estas otras democracias estarán representadas por los procesos constituyentes de Bolivia (2009), Ecuador (2008) y Venezuela (1999), los cuales se contraponen a la modernidad occidental y la imposición de su sentido común mediante sus fundamentos constitucionales refundacionales.

La crítica a los modelos de desarrollo y discursos desarrollistas vienen de la mano de Karen Wild. La crítica misma se ha instalado — siguiendo a Aníbal Quijano en sus análisis de la colonialidad del poder² - en América Latina y, pareciera que, a pesar de los diferentes discursos y teorías que han ido surgiendo desde la primera vez que este término apareciera —allá por 1949—, estos no han presentado una verdadera alternativa al discurso eurocéntrico y desarrollista. Wild, se vale de las críticas de diferentes movimientos sociales (feministas, ecologistas, indígenas, etc.) para presentar cuestionamientos radicales a la ideología del progreso y de la acumulación material. La autora lleva a cabo una lúcida crítica de las políticas y discursos de desarrollo de los gobiernos progresistas o de izquierdas. Según Wild, estos gobiernos, a pesar de asumir discursos críticos con los modelos tradicionales de desarrollo, lo acaban concibiendo como crecimiento económico ligado a las exportaciones de materias primas, aunque con mayor protagonismo estatal (neoextractivismo), no obstante, la extracción se realiza siguiendo con las prácticas empresariales tradicionales. A pesar de ser un modelo que continua con la dependencia extranjera, encuentra la inversión en políticas sociales su mejor defensa. Políticas, que en muchas ocasiones vienen a revertir las desigualdades producidas por el neoextractivismo.

Los cuatro ejes restantes analizan las problemáticas actuales del Uruguay. Los artículos acometen un análisis crítico de los logros y la agenda pendiente desde la llegada del Frente Amplio al gobierno en el 2005.

Desde la economía política, Óscar Mañán y Nicolás Marrero, realizan una dura crítica al modelo de desarrollo de los gobiernos del Frente Amplio durante la última década en Uruguay, el cual califican de "extractivista, extrovertido y depredador y dependiente de la Inversión Extranjera Directa” (p. 87), a la cual se incentiva mediante ventajas fiscales y la potencialización de zonas francas liberes de impuestos. Así pues, a pesar de encontrar su legitimidad en los datos macroeconómicos y las políticas sociales, el modelo de desarrollo continúa siendo el mismo que el del periodo neoliberal.

Entrecomillado del autor.

Aníbal Quijano: “El fantasma del desarrollo en América Latina”. Revista Venezolana de Economía y Ciencias Sociales, vol. 6, núm. 2, 2000, pp. 73-90. [Disponible en URL: <http://www.ceapedi.com.ar/imagenes/biblioteca/libros/56.pdf>. Consultado el 29 de Marzo de 2016]. 
La acción colectiva organizada es aborda desde el sindicalismo en el tercer eje del trabajo. Los artículos que componen el eje realizan un recorrido histórico de las luchas del movimiento sindical a lo largo del siglo XX y hasta el cambio de escenario político y económico que supuso la llegada del Frente Amplio, momento que significó una mejora en condiciones salariales con la regulación estatal de los Consejos de Salarios, así como una mayor capacidad y fomento de la negociación colectiva. Mención aparte merece el artículo dedico al Sindicato Único de Trabajadoras Domésticas, el cual realiza una interesante aproximación a este sector que había permanecido fuera de cualquier regulación laboral hasta el 2006, lo que se tradujo, no sólo en las garantías necesarias para el ejercicio de sus derechos, sino en el reconocimiento de las trabajadoras domésticas como sujetos políticos e iguales al resto de los trabajadores.

La cuestión espacial se aborda, principalmente, a partir de las transformaciones urbanas debidas a las dinámicas capitalistas y al modelo de desarrollo estatal en la zona metropolitana de Montevideo, donde se evidencian las relaciones de poder a través de la neutralización y la desarticulación de sujetos colectivos en favor de los sectores dominantes y, esto con un papel activo del Estado, el cual, en términos lefevbrianos, abandona su "rol de garante del derecho la ciudad" (p. 189).

El último eje ahonda en el discurso y la práctica de la participación ciudadana en el desarrollo de políticas públicas y las luchas sociales surgidas desde la llegada al gobierno del Frente Amplio, mediante varios estudios de caso.

Las transformaciones de los últimos años en el escenario político, social y económico en la región, son analizadas desde una perspectiva crítica e interdisciplinar, evidenciando las contradicciones discursivas y las prácticas políticas de los gobiernos denominados progresistas o de izquierda. El trabajo aborda desde diferentes enfoques teóricos y metodológicos los logros y agendas pendientes de estos gobiernos, poniendo el foco en el papel de los movimientos sociales y las organizaciones en un contexto siempre cambiante, y en ocasiones ya no tan favorable.

Como es habitual en los libros de autoría conjunta, no se abordan en todas sus dimensiones los temas tratados, pero son trabajos que invitan a profundizar, $\mathrm{y}$ abren las puertas a nuevas investigaciones.

Umelfadli Malainin Chibih Universidad Complutense de Madrid Email: fadala.mb@gmail.com 